\title{
KARAKTERISTIK STRUKTUR KOMUNITAS MAKROZOOBENTOS DI PERAIRAN EKOSISTEM MANGROVE GILI LAWANG, LOMBOK TIMUR
}

\author{
Characteristics Macrozoobenthos Structure Community in Gili Lawang Mangrove Ecosystem \\ Waters, East Lombok \\ Niechi Valentino $^{1^{\star}}$, Sitti Latifah ${ }^{1}$, Budhy Setiawan $^{1}$, Eni Hidayati ${ }^{1}$, Zata Yumni Awanis $^{2}$, \\ Hayati $^{3}$ \\ ${ }^{1}$ Program Studi Kehutanan, Fakultas Pertanian, Universitas Mataram \\ Jalan Pendidikan No. 37 Mataram 83125 \\ ${ }^{2}$ Program Studi Matematika, FMIPA, Universitas Mataram \\ Jalan Majapahit No. 62 Mataram 83125 \\ ${ }^{3}$ Program Studi Agribisnis, Fakultas Pertanian, Universitas Mataram \\ Jalan Majapahit No. 62 Mataram 83125 \\ *Email: niechivalentino@gmail.com
}

Diterima : 22/02/2022, Direvisi : 01/03/2022, Disetujui : 06/03/2022

\begin{abstract}
The role of the mangrove ecosystem as an ecological link through high productivity compared to other ecosystems has had a major impact on the existence of the mangrove ecosystem distribution. This study aims to find out the type of organic ingredient content and abundance of macrozoobenthos and find out the relationship of organic ingredient content to the abundance of macrozoobenthos. The research was carried out in November 2021 using a purposive sampling technique method with a total of 5 stations. The samples taken were the sediments substrate and macrozoobenthos. The results shown that the organic content is dominated by saturated textures, muddy sand textures and saturated clay textures with an average organic content ranging from $1.24 \%$ - 1.90\%. There were 15 types of macrozoobenthos found and dominated by the Gastropod class with an average abundance of macrozoobenthos ranging from $202 \mathrm{ind} / \mathrm{m}^{2}-525 \mathrm{ind} / \mathrm{m}^{2}$. The types of macrozoobenthos found were Nassarius distortus, Anadara sp, Mesodesma sp, Mytillus sp, Donax sp, Abra soyoae, Cerithideopsilla djadjariensis, Telescopium telescopium, Cassidula nucleus, Cassidula angulifera, Litttoridina sp., Potamopyrgus sp., Melanoides sp., Battilaria zonalis dan Lumbriculus sp. The effect of organic matter content on the abundance of macrozoobenthos by $10.7 \%$ and $89.3 \%$ was more influenced by physic-chemical factors in Gili Lawang waters.
\end{abstract}

Keywords: mangrove ecosystem; organic matters; makrozoobenthos; gili lawang

\begin{abstract}
ABSTRAK
Peranan ekosistem mangrove sebagai mata rantai ekologis melalui produktivitas tinggi dibandingkan ekosistem lainnya telah memberikan pengaruh besar terhadap eksistensi
\end{abstract}


keberadaan distribusi ekosistem mangrove. Penelitian ini bertujuan untuk mengetahui jenis kandungan bahan organik dan struktur komunitas makrozoobentos serta mengetahui hubungan kandungan bahan organik terhadap struktur komunitas makrozoobentos. Pelaksanaan penelitian dilakukan pada bulan November 2021 dengan menggunakan teknik purposive sampling method yang berjumlah 5 titik pengamatan. Sampel yang diambil adalah substrat sedimen dan makrozoobentos. Hasil penelitian menunjukkan bahwa kandungan bahan organik didominasi oleh tekstur berpasir, tekstur pasir berlumpur dan tekstur liat berpasir dengan persentase kandungan bahan organik berkisar antara $1.24 \%-1.90 \%$. Jenis makrozoobentos yang ditemukan sebanyak 15 jenis dan didominasi oleh kelas Gastropoda dengan kelimpahan rata-rata makrozoobentos berkisar antara $202 \mathrm{ind} / \mathrm{m}^{2}-525 \mathrm{ind} / \mathrm{m}^{2}$. Jenis makrozoobentos yang ditemukan yaitu Nassarius distortus, Anadara sp, Mesodesma sp, Mytillus sp, Donax sp, Abra soyoae, Cerithideopsilla djadjariensis, Telescopium telescopium, Cassidula nucleus, Cassidula angulifera, Litttoridina sp., Potamopyrgus sp., Melanoides sp., Battilaria zonalis dan Lumbriculus sp. Pengaruh kandungan bahan organik terhadap kelimpahan makrozoobentos sebesar $10.7 \%$ dan $89.3 \%$ lebih dipengaruhi oleh faktor fisikakimia perairan Gili Lawang.

Kata kunci: Ekosistem mangrove; bahan organik; makrozoobentos; gili lawang

\section{PENDAHULUAN}

Peranan ekosistem mangrove sebagai mata rantai ekologis melalui produktivitas tinggi dibandingkan ekosistem lainnya telah memberikan pengaruh besar terhadap eksistensi keberadaan distribusi ekosistem mangrove. Valentino (2017) menyebutkan dalam jangkauan geografis, luasan distribusi mangrove baik secara spasial dan temporal sangat dipengaruhi oleh keanekaragaman hayati, komposisi dan struktur populasi mangrove serta faktor-faktor didalamnya termasuk produktivitas mangrove yang mampu bertoleransi adaptif terhadap kondisi lingkungan dan iklim tertentu. Tingginya produktivitas mangrove diperoleh dari proses peluruhan atau penguraian bagian tubuh tumbuhan mangrove (daun, batang, bunga dan propagul) dalam bentuk bahan organik sedimen yang terurai oleh mikroorganisme melalui proses fisika, kimia dan biologi dan membentuk detritus sebagai sumber makanan bagi biota laut di ekosistem mangrove (Farooqui et al. 2014; Friesen et al. 2018; Muliawan et al. 2020). Vinh et al. (2020) juga menguatkan bahwa pada ekosistem mangrove, produktivitas mangrove dalam bentuk bahan organik sedimen merupakan campuran dari sumber allochthonous dan autochthonous yang berasal dari alga hingga tumbuhan tingkat tinggi.

Interaksi yang sangat kuat antara perairan laut, sungai dan teresterial terhadap keanekaragaman hayati dalam bentuk produktivitas menyebabkan ekosistem mangrove bersifat dinamis, labil dan kompleks. Kedinamisan ekosistem mangrove dikarenakan vegetasi mangrove terus tumbuh dan berkembang hingga mengalami suksesi dalam bentuk endapan lumpur yang perlahan-lahan berubah menjadi daerah semi teresterial (Heriyanto \& Subiandono, 2016), sementara dikatakan labil karena sangat sensitif terhadap gangguan (Mughofar et al. 2018). Sementara itu dikatakan kompleks dikarenakan kehidupan vegetasi mangrove ditunjang oleh endapan lumpur yang dibentuk oleh aktivitas struktur perakaran vegetasi mangrove itu sendiri dan proses dekomposisi bahan organik yang berasal dari peluruhan bunga, daun, ranting dan kulit batang sehingga berdampak langsung terhadap kepadatan organisme laut.

Fungsi bahan organik yang dihasilkan oleh ekosistem mangrove adalah sebagai indikator kualitas perairan dan pendukung kehidupan organisme yang hidup di lingkungan ekosistem mangrove (Karimah 2017). Namun apabila jumlah bahan organik yang masuk melebihi daya dukung perairan, maka kondisi lingkungan perairan menjadi rusak dan 
selanjutnya mengganggu kehidupan organisme yang hidup di dalamnya. Bashir et al. (2020) dan Rositasari (2020) menyebutkan tingginya konsentrasi bahan organik pada endapan lumpur akan menghasilkan eutrofikasi akibat terjadinya penipisan oksigen terlarut (hipoksia) berkepanjangan yang berpotensi menimbulkan kematian bagi vegetasi dan hewan air lainnya. Hasil penelitian Mateo-Sagasta et al. (2017) telah menunjukkan 415 wilayah pesisir teridentifikasi mengalami eutrofikasi dan 169 diantaranya telah mengalami hipoksia. Lebih lanjut lagi, Rositasari (2020) menyebutkan bahwa hipoksia di perairan disebabkan adanya akselarasi kegiatan industrialisasi dan pertanian modern melalui aktivitas antropogenik yang menimbulkan polutan ke pesisir dalam berbagai skala.

Salah satu organisme yang erat kaitannya dengan bahan organik sedimen adalah makrozoobentos. Gultom et al. (2018) menjelaskan bahwa makrozoobentos memiliki kemampuan untuk mengakumulasi suatu bahan pencemar di dalam tubuhnya melalui proses dekomposisi dan mineralisasi substrat organik sekaligus sumber pakan bagi ikan demersal. Informasi penting yang dapat digunakan untuk mengetahui kondisi kualitas perairan adalah dengan melihat struktur komunitas makrozzobentos. Hal ini disebabkan komposisi maupun kepadatan makrozoobentos tergantung pada toleransi atau sensitivitasnya terhadap perubahan lingkungan. Oleh karena itu, penelitian ini bertujuan mengetahui jenis kandungan bahan organik dan struktur komunitas makrozoobentos serta mengetahui hubungan kandungan bahan organik terhadap struktur komunitas makrozoobentos.

\section{METODE}

Pelaksanaan penelitian dilakukan pada bulan November 2021 di perairan Gili Lawang, Desa Sugian, Kabupaten Lombok Timur, Nusa Tenggara Barat (Gambar 1). Lokasi sampling ditentukan dengan menggunakan teknik purposive sampling method, yaitu menentukan titik sampling secara sengaja berdasarkan tujuan tertentu (Sofian, 2018; Barus et al. 2020; Tari et al. 2020). Penentuan titik sampling ini dipilih berdasarkan keterwakilan area contoh, kepadatan vegetasi, kemampuan peneliti dalam menjangkau lokasi pengamatan dan keselamatan peneliti.

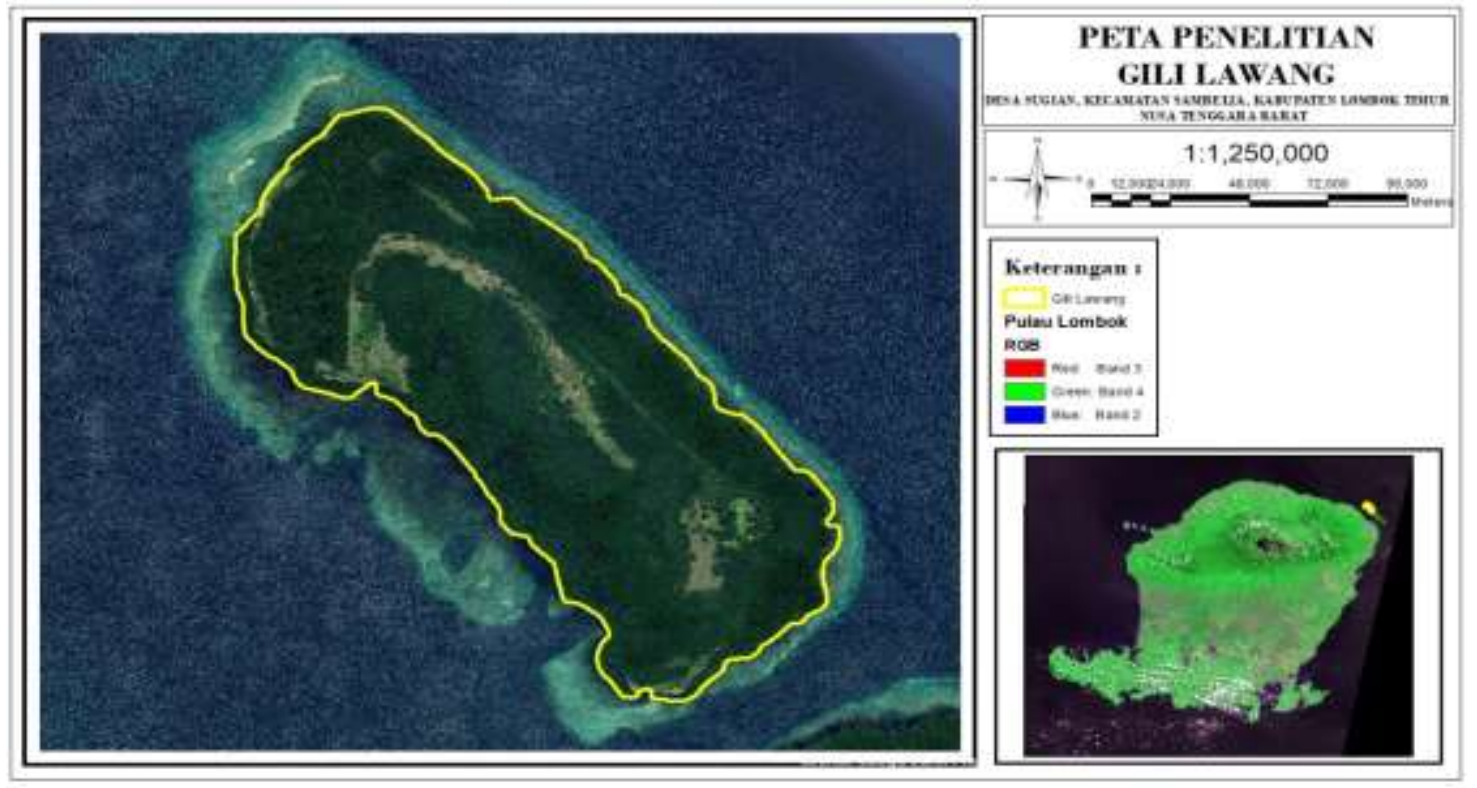

Gambar 1. Lokasi penelitian

Figure 1. Research location 
Berdasarkan survei lapangan, lokasi penelitian dibagi menjadi 5 stasiun. Stasiun 1, 2 dan 3 mewakili kepadatan vegetasi terdiri dari dua genus vegetasi (genus Rhizophora sp. dan Bruguiera sp.) dan stasiun 4 dan 5 diletakkan pada lokasi yang memiliki kepadatan vegetasi lebih dari dua genus vegetasi mangrove (genus Rhizophora sp., Bruguiera sp., Avicennia sp., dan Sonneratia sp.). Kusmana (2017) menyebutkan setiap stasiun pengamatan memiliki panjang $10 \times 200$ meter ditarik tegak lurus memotong kontur dari garis pantai menuju ke arah daratan untuk memudahkan pengambilan data di lapangan (Gambar 2). Letak geografis stasiun pengamatan disajikan pada Tabel 1.

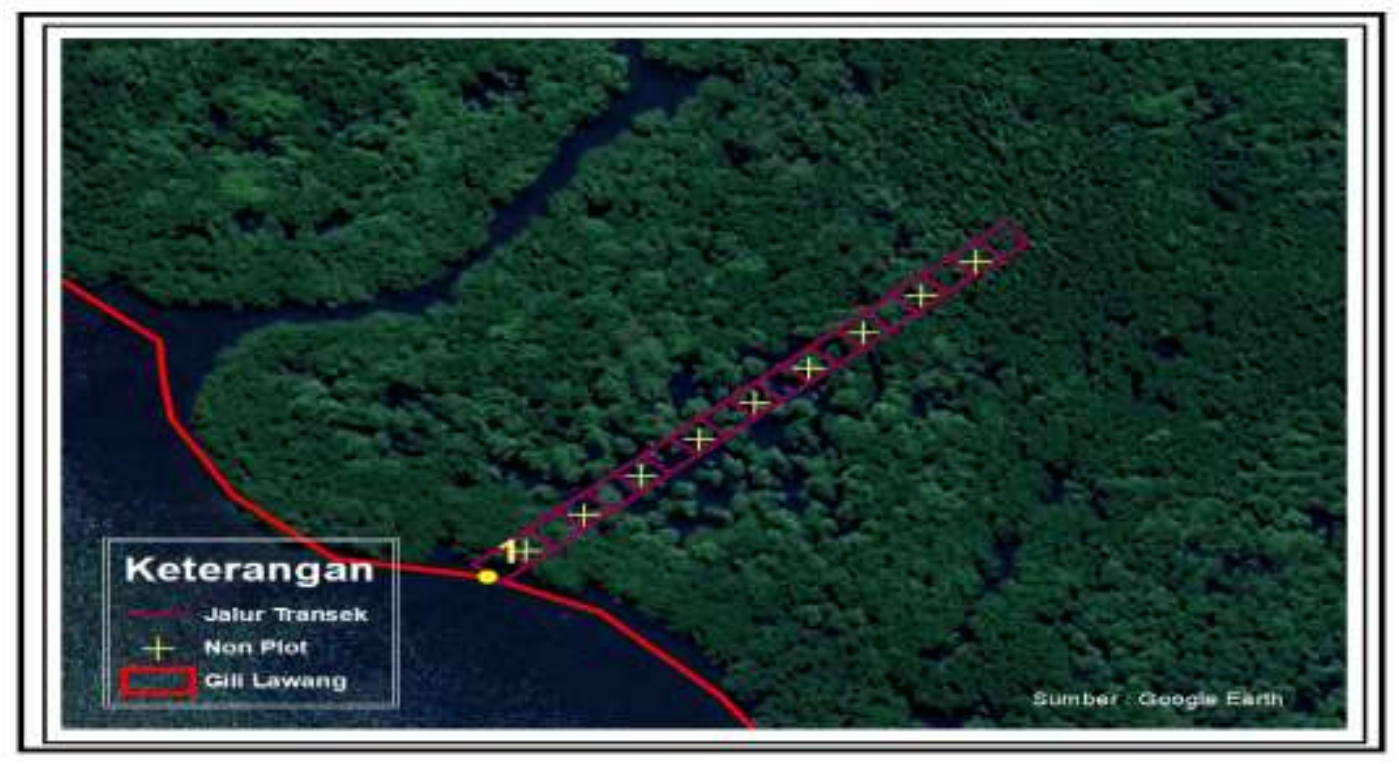

Gambar 2. Contoh letak stasiun plot pengamatan

Figure 2. An example of the location of observation plot station

Tabel 1. Letak geografis lokasi pengamatan

Table 1. Geographical location of observation plots

\begin{tabular}{|c|c|c|}
\hline Stasiun & Titik Koordinat & Kepadatan Vegetasi Dominan \\
\hline 1 & $\begin{array}{l}\text { E } 116^{0} 69^{\prime} 47.65^{\prime \prime} \\
\text { S } 08^{0} 29^{\prime} 67.58^{\prime \prime}\end{array}$ & $\begin{array}{l}\text { Genus Rhizophora sp. (Rhizophora mucronata, Rhizophora } \\
\text { apiculata, Rhizophora stylosa) dan Bruguiera sp. (Bruguiera } \\
\text { gymnorrhiza) }\end{array}$ \\
\hline 2 & $\begin{array}{l}\text { E } 116^{0} 68^{\prime} 82.75^{\prime \prime} \\
\text { S } 08^{0} 28^{\prime} 24.50^{\prime \prime}\end{array}$ & $\begin{array}{l}\text { Genus Rhizophora sp. (R. mucronata, R. apiculata, R. stylosa) } \\
\text { dan Bruguiera sp. (B. gymnorrhiza) }\end{array}$ \\
\hline 3 & $\begin{array}{l}\text { E } 116^{0} 70^{\prime} 92.30^{\prime \prime} \\
\text { S } 08^{0} 30^{\prime} 93.00^{\prime \prime}\end{array}$ & $\begin{array}{l}\text { Genus Rhizophora sp. (R. mucronata, } R . \text { apiculata) dan } \\
\text { Sonneratia sp. (S. alba) }\end{array}$ \\
\hline 4 & $\begin{array}{l}\text { E } 116^{0} 71^{\prime} 17.05^{\prime \prime} \\
\text { S 08030'21.90" }\end{array}$ & $\begin{array}{l}\text { Genus Rhizophora sp. (R. mucronata, R. apiculata, R. stylosa) } \\
\text { dan Bruguiera sp. (B. gymnorrhiza, B. cylindrica), Sonneratia sp. } \\
\text { (S. alba) dan Avicennia sp. (A. marina). }\end{array}$ \\
\hline 5 & $\begin{array}{l}\text { E 116070'46.00"' } \\
\text { S 08 } 29^{\prime} 21.10^{\prime \prime}\end{array}$ & $\begin{array}{l}\text { Genus Rhizophora sp. (R. mucronata, R. apiculata) dan Bruguiera } \\
\text { sp. (B. gymnorrhiza, B. cylindrica) dan Avicennia sp. (A. marina). }\end{array}$ \\
\hline \multicolumn{3}{|c|}{ Sumber: Data Primer (2021) } \\
\hline $\mathrm{P}$ & ran kualitas & an dilakukan bersan \\
\hline
\end{tabular}


Sampel makrozoobentos diambil menggunakan surber net dan disimpan di dalam kantong sampel yang ditambahkan alkohol $70 \%$ untuk menjaga keawetan sampel makrozoobentos. Sampel makrozoobentos diidentifikasi menggunakan buku identifikasi karangan Gosner (1971) dan Dharma (1988). Selanjutnya kelimpahan jenis makrozoobentos diolah dengan mengacu pada penelitian (Sidik et al. (2016) sedangkan indeks ekologi mengikuti formula pada penelitian Latifah et al. (2021). Pengolahan data dilakukan di Laboratorium Manajemen Hutan Program Studi Kehutanan Fakultas Pertanian Universitas Mataram.

Bahan organik total (BOT) diambil menggunakan core yang terbuat dari pipa paralon berukuran diameter 2 inci dengan panjang $20 \mathrm{~cm}$. Sampel sedimen diambil sebanyak 3 kali pengulangan pada setiap genus vegetasi yang berada pada setiap stasiun yang mewakili bagian depan, tengah dan belakang sehingga total sampel yang diperoleh sebanyak 39 sampel. Sampel sedimen yang diambil di lapangan disimpan di dalam cool box yang berisi es untuk menghindari terjadinya penguraian oleh bakteri. Sampel sedimen kemudian dibawa ke Laboratorium Kimia dan Biologi Tanah Fakultas Pertanian Universitas Mataram untuk diuji menggunakan metode pembakaran dengan suhu tinggi (loss on ignitation) dengan merujuk pada penelitian Heiri et al. (2001).

Selanjutnya hubungan antara bahan organik sedimen terhadap struktur komunitas makrozoobentos dianalisis dengan regresi linear sederhana melalui software SPSS 16.0 sehingga dapat diketahui variabel yang mempengaruhi dan variabel yang dipengaruhi (Santoso, 2011).

\section{HASIL DAN PEMBAHASAN}

\section{Kondisi Fisika-Kimia Perairan}

Hasil pengukuran kualitas air (parameter fisika dan kimia) Gili Lawang diperoleh dari nilai rata-rata tiga kali pengulangan di setiap stasiun. Hasil pengamatan di lapangan terhadap parameter kualitas air dapat dilihat pada Tabel 2.

Tabel 2. Parameter fisika-kimia perairan Gili Lawang

Table 2. Physical-chemical parameters of Gili Lawang waters

\begin{tabular}{lccccc}
\hline \multicolumn{1}{c}{ Parameter } & \multicolumn{5}{c}{ Stasiun } \\
\cline { 2 - 6 } & $\mathrm{I}$ & $\mathrm{II}$ & $\mathrm{III}$ & $\mathrm{IV}$ & $\mathrm{V}$ \\
\hline Arus $(\mathrm{m} / \mathrm{det})$ & 0.16 & 0.17 & 0.17 & 0.18 & 0.19 \\
\hline Suhu $\left({ }^{\mathrm{O}} \mathrm{C}\right)$ & 28 & 27 & 28 & 28 & 29 \\
\hline Salinitas $(\% \mathrm{o})$ & 21 & 20 & 22 & 24 & 25 \\
\hline Kecerahan $(\mathrm{m})$ & 0.75 & 0.75 & 0.44 & 0.25 & 0.5 \\
\hline $\mathrm{pH}$ & 8 & 8 & 8 & 7 & 8 \\
\hline $\mathrm{DO}(\mathrm{mg} / \mathrm{l})$ & 5.9 & 4.9 & 5.8 & 6.1 & 5.7 \\
\hline Kedalaman $(\mathrm{cm})$ & 72 & 87 & 48 & 45 & 62 \\
\hline \multicolumn{1}{c}{ Sumber: Data Primer (2021) } & & & & &
\end{tabular}

Tabel 2 menunjukkan arus laut tertinggi didapatkan pada stasiun $\vee$ sebesar $0.19 \mathrm{~m} / \mathrm{detik}$ sedangkan arus laut terendah dijumpai pada stasiun I sebesar $0.16 \mathrm{~m} / \mathrm{detik}$. Hal ini menunjukkan bahwa kecepatan arus di perairan Gili Lawang dikategorikan sebagai arus lambat. Yunitawati et al. (2012) menjelaskan bahwa arus laut dapat dibedakan berdasarkan tipe arusnya, menjadi (1). Arus laut sangat lambat berada $<0.1 \mathrm{~m} /$ detik, (2). Arus laut lambat berada antara $0.1 \mathrm{~m} /$ detik $-0.2 \mathrm{~m} /$ detik, (3). Arus laut sedang berada antara $0.2 \mathrm{~m} /$ detik -0.5 $\mathrm{m} /$ detik, (4). Arus laut cepat berada pada rentang $0.5 \mathrm{~m} /$ detik $-1 \mathrm{~m} / \mathrm{detik}$, dan (5). Arus laut sangat cepat berada $>1 \mathrm{~m} /$ detik. Selain itu, arus laut lambat merupakan salah satu tipe khas 
dari perairan pulau-pulau kecil (Yolanda et al. 2020; Muzammil et al. 2021). Gultom et al. (2018) juga menambahkan bahwa distribusi dan terbentuknya sedimen yang didominasi lumpur atau lempung sebagai habitat makrozoobentos dipengaruhi oleh arus lambat. Selanjutnya, pada pengukuran suhu perairan Gili Lawang menunjukkan suhu tertinggi dijumpai pada stasiun $\mathrm{V}$ sebesar $29^{\circ} \mathrm{C}$ sedangkan suhu terendah dijumpai pada stasiun II yaitu sebesar $27^{\circ} \mathrm{C}$. Fadilah et al. (2016) menyebutkan bahwa pertumbuhan makrozoobentos dipengaruhi oleh suhu optimal pada rentang kisaran suhu antara $20^{\circ} \mathrm{C}-30^{\circ} \mathrm{C}$.

Tabel 2 juga menunjukkan nilai salinitas yang bervariasi di setiap stasiun. Salinitas tertinggi ditemukan pada stasiun $\mathrm{V}$ sebesar $25 \%$ dan terendah ditemukan pada stasiun II sebesar $20 \%$. Variasi salinitas ini diduga dipengaruhi oleh pasang surut di lokasi penelitian, tetapi masih toleran terhadap perkembangbiakan makrozoobentos. Hasil penelitian Asriani (2012) menunjukkan bahwa kisaran salinitas yang baik untuk perkembangbiakan makrozoobentos berada pada kisaran $15 \%$ - $35 \%$. Selanjutnya, hasil pengukuran kecerahan selama penelitian berkisar $0.25 \mathrm{~m}-0.75 \mathrm{~m}$ dengan kedalaman berkisar $0.45 \mathrm{~m}-0.87 \mathrm{~m}$. Tinggi rendahnya kecerahan sangat dipengaruhi oleh partikel yang tersuspensi didalamnya, semakin sedikit partikel yang tersuspensi maka kecerahan air akan semakin tinggi (Yulma et al. 2013).

Gultom et al. (2018) menyebutkan bahwa oksigen terlarut (DO) merupakan salah satu penentu baik buruknya kualitas perairan dalam kehidupan akuatik. Hasil penelitian menunjukkan kandungan oksigen terlarut (DO) berada pada kisaran $4.9 \mathrm{mg} / \mathrm{l}-6.1 \mathrm{mg} / \mathrm{l}$. Apriadi et al. (2020) menjelaskan organisme makrozoobentos membutuhkan oksigen untuk pembakaran dalam menunjang aktivitas kehidupan. Selain itu oksigen terlarut juga dibutuhkan oleh makrozoobentos dalam proses dekomposisi organik (Safitri et al. 2021). Selanjutnya, parameter fisika-kimia perairan yang berpengaruh adalah $\mathrm{pH}$. Yulma et al. (2013) menyebutkan bahwa derajat keasaman $(\mathrm{pH})$ adalah jumlah ion organik yang terdapat pada larutan. Hasil penelitian menunjukkan nilai $\mathrm{pH}$ berkisar antara $7.0-8.0$. Hal ini menunjukkan bahwa $\mathrm{pH}$ pada penelitian tidak berbeda jauh terhadap $\mathrm{pH}$ normal perairan di wilayah Indonesia, mengingat $\mathrm{pH}$ perairan Indonesia berada pada rentang 6.0 - 8.5 (Aksornkoae 1993).

\section{Bahan Organik Sedimen}

Pengambilan data di lapangan menunjukkan rata-rata kandungan bahan organik di Gili Lawang organik sama berkisar antara $1.24 \%-1.90 \%$ (Tabel 3). Kandungan bahan organik tertinggi terdapat pada stasiun IV sebesar $1.90 \%$. Tinggi dan rendahnya kandungan bahan organik sedimen diduga karena peluruhan bagian tumbuhan yang tertimbun dan membentuk sedimentasi substrat selama jangkauan waktu yang lama. Shalihah et al. (2017) menyebutkan substrat memiliki peran penting bagi kehidupan makrozoobentos karena substrat yang halus cenderung untuk mengakumulasi bahan organik, sehingga cukup banyak makanan yang potensial bagi makrozoobentos. Barus (2020) juga menambahkan bahwa substrat halus seperti substrat pasir memiliki ketersediaan oksigen yang cukup tinggi karena substrat pasir mempunyai rongga udara.

Tabel 3. Nilai rata-rata persentase kandungan bahan organik sedimen pada setiap stasiun Table 3. The average value of the percentage of sedimentary organic matter content at each station

\begin{tabular}{ccc}
\hline Stasiun & Rata-rata $(\%)$ & Kriteria (Reynold, 1971) \\
\hline I & 1.89 & Rendah \\
II & 1.24 & Rendah \\
\hline III & 1.46 & Rendah \\
\hline IV & 1.90 & Rendah \\
\hline V & 1.75 & Rendah \\
\hline
\end{tabular}

Sumber: Data Primer (2021) 


\section{Tekstur Sedimen} Tabel 4.

Persentase dan tipe tekstur sedimen pada tiap stasiun di Gili Lawang disajikan pada

Tabel 4. Persentase dan tipe tekstur sedimen pada tiap stasiun

Table 4. The percentage and sedimentary texture types at each station

\begin{tabular}{ccccl}
\hline Stasiun & & Fraksi Sedimen & Tipe Tekstur \\
\cline { 2 - 4 } & Sand (Pasir) $\%$ & Silt (lumpur) $\%$ & Clay (Liat) $\%$ & \\
\hline I & 152.69 & 73.31 & 7.33 & Pasir Berlumpur \\
\hline II & 75.42 & 2.69 & 155.23 & Liat Berpasir \\
\hline IV & 132.47 & 4.26 & 96.61 & Liat Berpasir \\
\hline V & 222.58 & 9.56 & 1.19 & Pasir \\
\hline
\end{tabular}

Sumber: Data Primer (2021)

Tabel 4 menunjukkan bahwa jenis substrat yang dominan di perairan Gili Lawang adalah pasir $(75.42 \%-222.58 \%)$, lumpur $(2.69 \%-73.31 \%)$ dan liat $(1.19 \%-155.23 \%)$. Gambaran tipe sedimen yang berbeda untuk masing-masing stasiun pengamatan yaitu stasiun I (pasir berlumpur), stasiun II dan stasiun III (liat berpasir) sedangakan stasiun IV dan stasiun V (Pasir). Tipe sedimen pada stasiun I terbentuk pasir berlumpur dan pada stasiun IV, $V$ terbentuk pasir dikarenakan memiliki kecepatan arus yang lambat. Menurut Odum (1993) bahwa semakin tinggi kecepatan arus maka substrat dasar memiliki ukuran yang semakin besar. Maghfirah et al. (2014) menambahkan arus yang lambat membuat partikel halus yang berukuran kecil seperti pasir dan lumpur mudah mengendap di dasar perairan sehingga substrat yang terbentuk adalah dominan lempung yang memiliki kandungan organik cukup tinggi.

\section{Kelimpahan Jenis Makrozoobentos}

Pada lokasi penelitian di Gili Lawang ditemukan 15 jenis yang terdiri dari 2 filum yaitu Molusca dan Oligochaeta. Kelas Gastropoda paling banyak dijumpai hampir merata pada setiap penelitian dan ditemukan sebanyak 8 jenis sedangkan kelas Bivalvia ditemukan sebanyak 6 jenis dan 1 jenis dari kelas Tubificinae. Hal ini menunjukkan bahwa Gastropoda mampu beradaptasi terhadap kondisi lingkungannya dan ditunjukkan oleh jenis Cerithideopsilla djadjariensis ditemukan pada setiap stasiun yang ada. Sebagaimana dalam penelitian Maghfirah et al. (2014) yang menyebutkan bahwa jenis-jenis Gastropoda memiliki fisiologi khusus untuk beradaptasi pada sedimen halus yaitu substrat pasir dan lumpur. Kumar \& Khan (2013) juga melaporkan dalam penelitiannya di India bahwa jenis Gastropoda melimpah banyak ditemukan pada ekosistem mangrove dengan substrat berpasir. Selain itu kelimpahan gastropoda dapat dijadikan sebagai indikator asosiasi dengan mangrove karena mudah identifikasi, ditemukan sepanjang tahun, toleran terhadap lingkungan dan memiliki mobilitas terbatas (Amin et al. 2009) dan meningkatnya kelimpahan jenis Gastropoda juga meningkat seiring bertambahnya usia vegetasi (Irma \& Sofyatuddin 2012).

Hasil pengamatan (Tabel 5) menunjukkan bahwa jumlah individu terbanyak terdapat pada stasiun IV yaitu $525 \mathrm{ind} / \mathrm{m}^{2}$ dengan 14 jenis makrozoobentos sedangkan kelimpahan makrozoobentos terendah ditemukan pada stasiun II sebesar $202 \mathrm{ind} / \mathrm{m}^{2}$ dengan 4 jenis yang ditemukan. Marwan (2012) menyatakan bahwa sumber nutrien bagi makrozoobentos terkandung di dalam substrat dasar yang terdapat pada bahan organik. Hasil perhitungan kelimpahan jenis secara detail dapat dilihat pada Tabel 5. 
Tabel 5. Kelimpahan dan jumlah jenis makrozoobentos pada setiap stasiun penelitian Table 5. The abundance and total number of macrozoobenthos species at each station

\begin{tabular}{|c|c|c|c|}
\hline Stasiun & Kelimpahan (ind $/ \mathrm{m}^{2}$ ) & Jumlah Jenis & Nama Jenis \\
\hline I & 354 & 7 & $\begin{array}{l}\text { Bivalvia (Nassarius distortus, Anadara sp.), } \\
\text { Gastropoda (Cerithideopsilla djadjariensis, } \\
\text { Telescopium telescopium, Battilaria zonalis, }\end{array}$ \\
\hline & & & $\begin{array}{l}\text { Littoridina sp., Cassidula angulifera, } \\
\text { Melanoides sp.) }\end{array}$ \\
\hline II & 202 & 4 & $\begin{array}{lll}\text { Bivalvia (Mytillus sp.), } & \text { Gastropoda } \\
\text { (Cerithideopsilla djadjariensis, } & \text { Telescopium } \\
\text { telescopium, Melanoides sp.) } & \end{array}$ \\
\hline III & 485 & 11 & $\begin{array}{lrr}\text { Bivalvia } & \text { (Mytillus sp., Anadara sp., Donax } \\
\text { sp.), } & \text { Gastropoda } & \text { (Cerithideopsilla }\end{array}$ \\
\hline & & & $\begin{array}{l}\text { djadjariensis, Telescopium telescopium, } \\
\text { Cassidula nucleus, Littoridina sp., Melanoides }\end{array}$ \\
\hline & & & $\begin{array}{l}\text { sp., Battilaria zonalis, Potamopyrgus sp., } \\
\text { Cassidula angulifera) }\end{array}$ \\
\hline IV & 525 & 14 & $\begin{array}{l}\text { Bivalvia (Anadara sp, Mesodesma sp, } \\
\text { Mytillus sp, Donax sp, Abra soyoae), } \\
\text { Gastropoda (Cerithideopsilla djadjariensis, } \\
\text { Telescopium telescopium, Cassidula nucleus, } \\
\text { Cassidula angulifera, Litttoridina sp., } \\
\text { Potamopyrgus sp., Melanoides sp., Battilaria } \\
\text { zonalis), Oligochaeta (Lumbriculus sp.) }\end{array}$ \\
\hline V & 453 & 9 & $\begin{array}{l}\text { Bivalvia (Mytllus sp., Donax sp., Anadara } \\
\text { sp.,), Gastropoda (Cerithideopsilla } \\
\text { djadjariensis, Battilaria zonalis, Littoridina sp., } \\
\text { Melanoides sp., Cassidula angulifera, } \\
\text { Potamopyrgus sp.,) }\end{array}$ \\
\hline
\end{tabular}

Sumber: Data Primer (2021)

\section{Indeks Ekologi}

Indeks ekologi merupakan indikator kestabilan ekosistem yang ditunjukkan melalui variabilitas keanekaragaman jenis, kemerataan jenis dan dominansi jenis. Indeks ekologi struktur komunitas makrozoobentos dapat diihat pada Tabel 6.

Tabel 6. Indeks ekologi makrozoobentos di Gili Lawang Table 6. Ecology index of macrozoobenthos at Gili Lawang

\begin{tabular}{cccc}
\hline Stasiun & H'$^{\prime}$ & $\mathrm{E}^{\prime}$ & $\mathrm{C}$ \\
\hline I & 0.65 & 0.49 & 0.69 \\
\hline II & 0.31 & 0.03 & 0.85 \\
\hline III & 1.17 & 0.11 & 0.46 \\
\hline IV & 1.45 & 0.13 & 1.97 \\
\hline V & 0.91 & 0.69 & 0.63 \\
\hline
\end{tabular}

Sumber: Data Primer (2021)

Table 6 menunjukkan bahwa keanekaraman jenis $\left(\mathrm{H}^{\prime}\right)$ makrozoobentos pada stasiun III dan IV dikategorikan keanekaragaman jenis sedang dikarenakan berada pada rentang nilai $1<$ $\mathrm{H}^{\prime}<3$ sedangkan keanekaragaman jenis pada stasiun I, II dan V dikategorikan rendah. Keanekaragaman jenis rendah dapat terjadi karena faktor lingkungan. Odum (1993) menyebutkan bahwa keanekaragaman spesies cenderung rendah dalam ekosistem yang mengalami tekanan secara fisik maupun kimia. Selain itu Desmawati et al. (2019) menambahkan bahwa tingkat keanekaragaman organisme yang terdapat di lingkungan perairan 
tertentu merupakan cerminan variasi toleransi jenis makrozoobentos terhadap parameter lingkungan. Pada stasiun IV memiliki keanekaragaman jenis lebih tinggi dibandingkan dengan stasiun lainnya dikarenakan kedalaman air lebih rendah atau termasuk kedalam perairan dangkal. Hal ini sesuai dengan penelitian Minggawati (2013) bahwa keanekaragaman jenis makrozoobentos paling tinggi ditemukan pada perairan yang dangkal akibat pengaruh intensitas matahari yang mampu menembus seluruh kedalaman perairan.

Berdasarkan hasil analisis indeks keseragaman (E') untuk setiap stasiun pengamatan berkisar antara 0.03 - 0.69 (Tabel 4), hal ini memperlihatkan bahwa jumlah antara spesies makrozobentos tidak tersebar secara merata dan tidak menunjukkan adanya variasi jenis makrozoobentos. Indeks keseragaman tertinggi berada pada stasiun $\mathrm{V}$ sebesar 0.69 dan yang terendah pada stasiun II sebesar 0.03. Selanjutnya, indeks dominansi (C) tertinggi ditemukan pada stasiun IV sebesar 1.97 dan indeks dominansi terendah ditemukan pada stasiun III sebesar 0.46. Tingginya nilai indeks dominasi pada stasiun IV disebabkan karena adanya satu spesies yang mendominasi yaitu Cerithideopsilla djadjariensis, dimana spesies tersebut memiliki kepadatan yang cukup tinggi dibandingkan dengan spesies lain. Hal ini disebabkan karena faktor lingkungan dan kondisi perairan seperti jenis substrat yang didominasi oleh pasir dan lumpur yang memiliki butiran yang sangat halus dan sangat mendukung untuk kehidupan genus Cerithidea (Marpaung et al. 2014). Haque \& Choudbury (2015) juga menambahkan bahwa tanah bersubstrat pasir dan lumpur yang berada pada pasang surut aktif, terpapar pada kedalaman dangkal atau diantara pneumathopora merupakan habitat yang kaya detritius yang disumbangkan oleh sistem mangrove.

\section{Asosiasi Kandungan Bahan Organik Sedimen Terhadap Struktur Komunitas Makrozoobenthos}

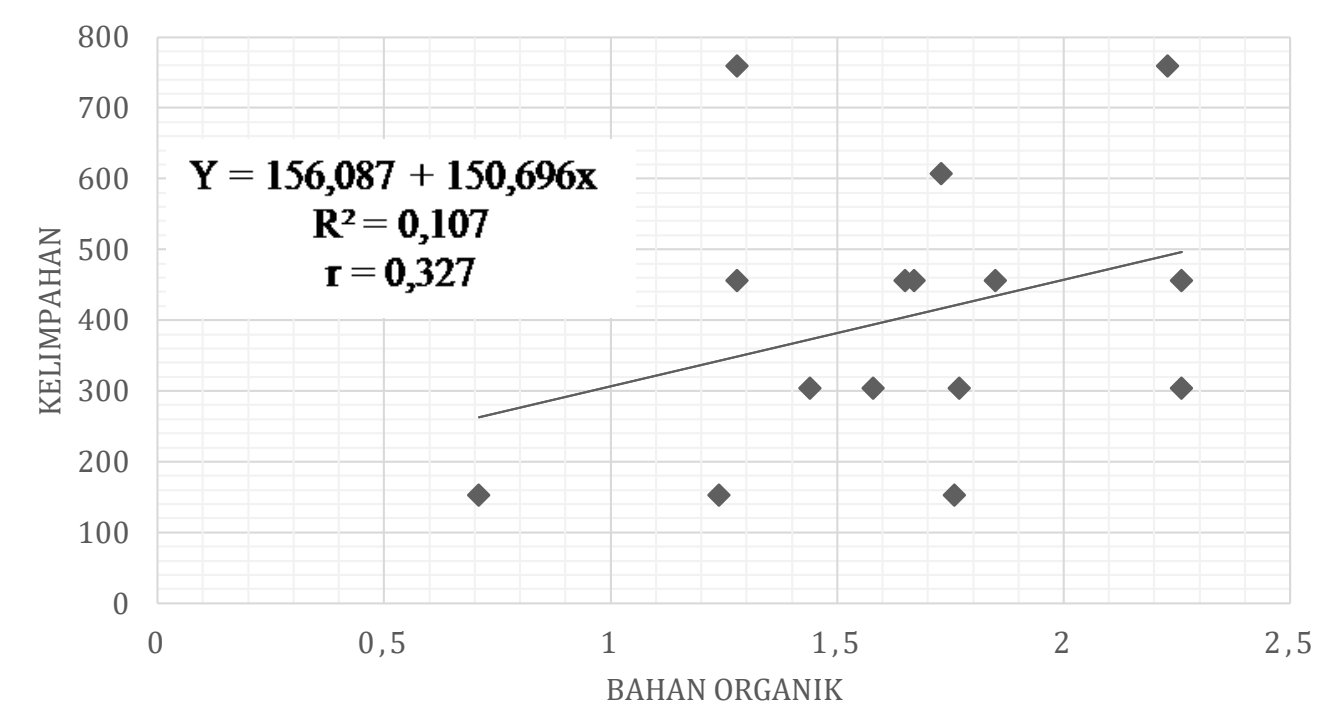

Gambar 3. Asosiasi Kandungan Bahan Organik Sedimen dan Struktur Komunitas Makrozoobentos

Figure 3. The association of sedimentary organic matter content and macrozoobenthos structure community

Gambar 3 menunjukkan model hubungan antara bahan organik sedimen terhadap struktur komunitas makrozoobentos yang ditunjukkan dengan persamaan $Y=$ $156,087+150,696 \mathrm{X}$ dengan koefisien determinasi sebesar 0.107 artinya adanya pengaruh 
bahan organik terhadap struktur komunitas makrozoobentos di perairan Gili Lawang sebesar $10.7 \%$ dan $\mathbf{8 9 . 3 \%}$ dipengaruhi oleh faktor lain yaitu faktor fisika-kima perairan Gili Lawang. Adelia et al. (2019) menyebutkan bahwa meningkatnya kelimpahan makrozoobentos dipengaruhi oleh suhu air, substrat dasar, oksigen terlarut, dan kandungan $\mathrm{pH}$ serta interaksi spesies dan adaptasi hidup masing-masing spesies pada ekosistem tersebut. Oleh karena itu, indikator keanekaragaman struktur komunitas makrozoobentos dan konektivitas keanekaragaman dengan lingkungannya dapat dijadikan landasan awal resiliensi dan jaminan terhadap ketidakpastian sistem ekologi pada ekosistem tertentu.

\section{KESIMPULAN}

Jenis tekstur sedimen yang terdapat di Gili Lawang, Lombok Timur didominasi oleh tekstur sedimen pasir, pasir berlumpur dan liat berpasir serta kandungan bahan organik sedimen berada pada rentang $1.24 \%$ - 1.90\% sehingga dikategorikan rendah. Kelimpahan makrozoobenthos tertinggi yang diperoleh yaitu $525 \mathrm{ind} / \mathrm{m}^{2}$ dijumpai pada stasiun IV dengan jenis yang ditemukan sebanyak 14 jenis antara lain Anadara sp, Mesodesma sp, Mytillus sp, Donax sp, A. soyoae, C. djadjariensis, T. telescopium, C. nucleus, C. angulifera, Litttoridina sp., Potamopyrgus sp., Melanoides sp., B. zonalis, Lumbriculus sp., sedangkan yang terendah ditemukan pada stasiun II yaitu sebesar $202 \mathrm{ind} / \mathrm{m}^{2}$ dengan jenis yang ditemukan sebanyak 4 jenis yaitu Mytillus sp., C. djadjariensis, T. telescopium, dan Melanoides sp. Selanjutnya asosiasi kandungan bahan organik sedimen terhadap struktur komunitas makrozoobenthos tergolong rendah dikarenakan hanya mampu mempengaruhi sebesar $10.7 \%$ dan $89.3 \%$ struktur komunitas makrozoobentos dipengaruhi oleh faktor fisika-kima perairan Gili Lawang.

\section{DAFTAR PUSTAKA}

Adelia, D., Adi, W., Adibrata, S. (2019). Keanekaragaman dan kelimpahan makrozoobentos di pantai Batu Belubang Bangka Tengah. Jurnal Sumberdaya Perairan, 13(1), 67-79.

Aksornkoae, S. (1993). Ecology and Management of Mangrove. Bangkok: IUCN.

Amin, B., Ismail, A., Arshad, A., Yap, C.K., Kamarudin, M.S. (2009). Gastropod assemblages as indicators of sediment metal contamination in mangroves of Dumai, Sumatra, Indonesia. Water Air Soil Pollution. 201(4), 9-18.

Apriadi, T., Muzammil, W., Melani, W.R., Safitri, A. (2020). Struktur komunitas makrozoobenthos di aliran sungai di Senggarang, Pulau Bintan, Kepulauan Riau. Jurnal IImu-IImu Perairan, Pesisir dan Perikanan, 9(1), 119-130.

Barus, B.S., Munthe, R.Y., Bernando, M. (2020). Kandungan karbon organik total dan fosfat pada sedimen di perairan muara sungai Banyuasin, Sumatera Selatan. Jurnal IImu dan Teknologi Kelautan Tropis, 12(2), 395-406.

Bashir, I., Lone, F.A., Bhat, R.A., Mir, S.A., Dar, Z.A., Dar, S.A. (2020). Concerns and threats of contamination on aquatic ecosystems. Dalam K.R. Hakeem, R.A. Bhat, \& H. Qadri (Eds.), Bioremidiation and Biotechnology: Sustainable Approaches to Polution Degradation (hlm. 1-26). Switzerland: Springer.

Desmawati, I., Adany, A., Java, C.A. (2019). Studi awal makrozoobentos di kawasan wisata sungai kalimas, Monumen Kapal Selam Surabaya. Jurnal Sains dan Seni ITS, 8(2), 23373520.

Dharma, B. (1988). Siput dan Kerang Indonesia. Jakarta: Lembaga Ilmu Pengetahuan Indonesia. 
Fadillah, N., Patana., Dalimunthe, M. (2016). Struktur komunitas makrozoobentos sebagai indikator perubahan kualitas perairan di sungai Belawan kecamatan Pancur Batu kabupaten Deli Serdang. Jurnal Aquacoastmarine, 11(1),

Farooqui, Z., Siddiqui, P.J.A., Rasheed, M. (2014). Changes in Organic, Inorganic contents, Carbon Nitrogen ratio in decomposing Avicennia marina and Rhizophora mucronata leaves on tidal mudflats in Hajambro creek, Indus delta, Pakistan. The Journal of Tropical Life Science. 4(1), 37-45.

Friesen, S.D., Dunn, C., Freeman, C. (2018). Decomposition as a regulator of carbon accretion in mangroves: a review. Ecological Engineering, 114, 173-178.

Gosner, K. L. (1971). Guide to Identification of Marine and Estuarine Invertebrates. USA: Jhon Wiley and Sons, Inc.

Gultom, C.R., Muskananfola, M.R., Purnomo, P.W. (2018). Hubungan kelimpahan makrozoobenthos dengan bahan organik dan tekstur sedimen di kawasan mangrove di desa Bedono kecamatan Sayung kabupaten Demak. Management of Aquatic Resource Journal (MAQUARES), 7(2), 172-179. https://doi.org/10.14710/mari.v7i2.22539

Haque, H., Choudhury, A. (2015). Ecology and behavior of Telescopium telescopium (Linnaeus, 1758), (Mollusca: Gastropoda: Potamididae) from Chemaguri mudflats, Sagar Island, Sundarbans, India. Int. J. Eng. Sci. Invention, 4(4), 16-21.

Heiri, O., Lotter, A.F., Lemcke, G. (2001). Loss on ignition as a method for estimating organic and carbonate content in sediment: reproducibility and comparability of result. Journal of Paleolimnology. 25: 101-110.

Heriyanto, N.M., Subiandono, E. (2016). Peran biomassa mangrove dalam menyimpan karbon di Kubu Raya, Kalimantan Barat. Jurnal Analisis Kebijakan Kehutanan, 13(1), 1-12. http://dx.doi.org/10.20886/jakk.2016.13.1.1-12

Irma, D., Sofyatuddin, K. (2012). Diversity of Gastropods and Bivalves in mangrove ecosystem rehabilitation areas in Aceh Besar and Banda Aceh districts, Indonesia. AACL, 5(2), 55-59.

Karimah. (2017). Peran ekosistem hutan mangrove sebagai habitat organisme laut. Jurnal Biologi Tropis, 17(2), 51-58. http://dx.doi.org/10.29303/jbt.v17i2.406.

Kumar, P.S., Khan, A.B. (2013). The distribution and diversity of benthic macroinvertebrate fauna in Pondicherry mangroves, India. Aquatic Biosystem. 9, 1-15.

Kusmana, C. (2017). Metode Survei dan Intrepetasi Data Vegetasi. Bogor: Penerbit IPB Press. Latifah, S., Valentino, N., Setiawan, B., Muddofir, M.R.T., Hidayati, E., Nuraini., Putra, T.Z. (2021). Species composition, structure and endemicity of flora Malesiana in the Udayana urban forest, Mataram City. IOP Conf. Series: Earth and Environmental Science, 637, 116. doi:10.1088/1755-1315/637/1/012088.

Magfirah, Emiyarti, Haya, L.M.Y. (2014). Karakteristik sedimen dan hubungannya dengan struktur komunitas makrozoobenthos di sungai Tahi Ite kecamatan Rarowatu kabupaten Bombana Sulawesi Tenggara. Jurnal Mina Laut Indonesia, 4(14), 117-131.

Marpaung, A.A.F., Yasir, I., Ukkas, M. (2014). Keanekaragaman makrozoobenthos di ekosistem mangrove silvofishery dan mangrove alami di Kawasan Ekowisata Pantai Boe, Kabupaten Takalar, Sulawesi Selatan. Bonoworo Wetlands, 4(1),1-11.

Marwan, S. (2012). Komunitas makrozoobentos di perairan estuari rawa gambut tripa provinsi Aceh. Jurnal Ilmiah Mahasiswa Kelautan dan Perikanan Unsyiah, 1(1), 134-145.

Mateo-Sagasta, J., Zadeh, S.M., Turral, H. (2017). Water Pollution from Agriculture: A Global Review. Rome: Food Agriculture Organization and International Water Management Institute.

Minggawati, I. (2013). Struktur komunitas makrozoobentos di perairan rawa banjiran sungai Rungan, kota Palangka Raya. Jurnal IImu Hewani Tropika, 2(2), 64-67.

Mughofar, A., Mohammad, M., Prabang, S. (2018). Zonasi dan komposisi vegetasi hutan mangrove pantai Cengkrong desa Karanggandu kabupaten Trenggalek provinsi Jawa 
Timur. Jurnal Pengelolaan Sumberdaya Alam dan Lingkungan, 8(1), 77-85. https://doi.org/10.29244/jpsl.8.1.77-85

Muliawan, R.E., Prartono, T., Bengen, D.G. (2020). Productivity and decomposition rate of Rhizophora mucronata and Avicennia alba litter based on environment characteristics in Muara Gembong. IOP Conf. Series: Earth and Environmental Science, 429, 1-13. doi:10.1088/1755-1315/429/1/012057.

Muzammil, W., Prihatin, N., Melani, W.R. (2021). Macrozoobenthos community structure and its relationship with waters quality of Kampung Baru, Sebong Lagoi Village, Bintan Regency. Journal of Tropical Fisheries Management. 5(1), 20-28.

Odum, E. P. (1993). Dasar-Dasar Ekologi (Terjemahan Samingan, T). Yogyakarta: Gadjah Mada University Press.

Rositasari, R. (2020). Ancaman hipoksia bagi ekosistem pesisir; penggunaan indeks AmmoniaElphidium (AE) sebagai proksi. Oseana, 45(1), 82-92.

Safitri, A., Melani, W.R., Muzammil, W. (2021). Komunitas makrozoobenthos dan kaitannya dengan kualitas air aliran sungai Senggarang, kota Tanjungpinang. Acta Aquatica: Aquatic Sciences Journal, 8(2), 103-108. https://ojs.unimal.ac.id/acta-aquatica/article/view/4782.

Santoso, S. (2011). Mastering SPSS. Jakarta: PT. Elex Media Komputindo.

Shalihah, H.N., Purnomo, P.W., Widyorini, N. (2017). Molluscs diversity based on sediment texture and organic matter content in Betahwalang Estuary, Demak Regency. Indonesian Journal of Fisheries Science and Technology (IJFST), 13(1), 58-64.

Sidik, R.Y., Dewiyanti, I., Octavina, C. (2016). Struktur komunitas makrozoobenthos dibeberapa muara sungai kecamatan Susoh kabupaten Aceh Barat Daya. Jurnal IImiah Mahasiswa Kelautan dan Perikanan Unsyiah, 1(2), 287- 296.

Sofian., Idris, M.H., Markum. (2018). Keanekaragaman spesies dan kontribusi hutan mangrove terhadap pendapatan masyarakat di desa Eyat Mayang, kecamatan Lembar kabupaten Lombok Barat. Jurnal Belantara, 1(1), 10-15.

Tari, K., Iswahyudi., Siregar, D.S. (2020). Kesesuaian kawasan untuk pengembangan ekowisata hutan mangrove Kuala Langsa. Jurnal Belantara, 3(2), 173-185.

Valentino, N. (2017). Taksonomi numerik berbasis karakter morfologi pada famili Rhizophoraceae di ekosistem mangrove. [Tesis]. Bogor: Sekolah Pascasarjana Institut Pertanian Bogor.

Vin, T.V., Allenbach, M., Linh, K.T.V., Marchand, C. (2020). Changes in leaf litter quality during its decomposition in a tropical planted mangrove forest (Can Gio, Vietnam). Frontiers in Environmental Science, 8(10), 1-15. doi: 10.3389/fenvs.2020.00010.

Yolanda, O.A.P., Melani, W.R., Muzammil, W. (2020). Karakteristik sedimen pada Perairan Sei Carang, Kota Tanjungpinang - Indonesia. Habitus Aquatica, 1(2), 11-20.

Yulma., Adiwilaga, E.M., Wardiatno, Y. (2013). Kontribusi bahan organik dari api-api (Avicennia marina) sebagai bahan evaluasi pengelolaan ekosistem mangrove: studi kasus kecamatan Labuhan Maringgai, kabupaten Lampung Timur. Bonorowo Wetlands, 3(1), 1229. doi: 10.13057/bonorowo/w030102.

Yunitawati., Sunarto., Hasan, Z. (2012). Hubungan antara Karakteristik Substrat dengan Struktur Komunitas Makrozoobenthos di Sungai Cantigi, Kabupaten Indramayu. Jurnal Perikanan dan Kelautan, 3(3), 221- 227. 